\title{
Engineered nanomaterial uptake and tissue distribution: from cell to organism
}

This article was published in the following Dove Press journal:

International Journal of Nanomedicine

26 August 2013

Number of times this article has been viewed

\author{
Helene Kettiger ${ }^{1, *}$ \\ Angela Schipanski ${ }^{2, *}$ \\ Peter Wick ${ }^{2}$ \\ Jörg Huwyler' \\ 'Department of Pharmaceutical \\ Sciences, Division of Pharmaceutical \\ Technology, University of Basel, \\ Basel, Switzerland; ' ${ }^{2}$ mpa, Swiss \\ Federal Laboratories for Materials \\ Science and Technology, Laboratory \\ for Materials-Biology Interactions, \\ St Gallen, Switzerland \\ *These authors contributed equally \\ to this work
}

\begin{abstract}
Improved understanding of interactions between nanoparticles and biological systems is needed to develop safety standards and to design new generations of nanomaterials. This article reviews the molecular mechanisms of cellular uptake of engineered nanoparticles, their intracellular fate, and their distribution within an organism. We have reviewed the available literature on the uptake and disposition of engineered nanoparticles. Special emphasis was placed on the analysis of experimental systems and their limitations with respect to their usefulness to predict the in vivo situation. The available literature confirms the need to study particle characteristics in an environment that simulates the situation encountered in biological systems. Phenomena such as protein binding and opsonization are of prime importance since they may have a strong impact on cellular internalization, biodistribution, and immunogenicity of nanoparticles in vitro and in vivo. Extrapolation from in vitro results to the in vivo situation in the whole organism remains a challenge. However, improved understanding of physicochemical properties of engineered nanoparticles and their influence on biological systems facilitates the design of nanomaterials that are safe, well tolerated, and suitable for diagnostic or therapeutic use in humans.
\end{abstract}

Keywords: biodistribution, cellular transport, cellular uptake, endocytosis, engineered nanomaterials, nanosafety

\section{Introduction}

Engineered nanomaterials (ENMs) are defined as materials composed of particles in an unbound state, or as an aggregate or agglomerate with one or more external dimensions in the size range from $1 \mathrm{~nm}$ to $100 \mathrm{~nm} .{ }^{1}$ Since active cellular uptake and tissue translocation of ENMs have been described for particles larger than $100 \mathrm{~nm},{ }^{2,3}$ we included literature reports on ENMs up to a size of $300 \mathrm{~nm}$. There are many examples of clinical uses of ENMs. The majority of ENMs used as therapeutics on the market and in late clinical studies have diameters above $100 \mathrm{~nm} .{ }^{4}$ Small particles with a size of less than $2 \mathrm{~nm}$ show passive uptake into erythrocytes. ${ }^{27}$ However, uptake mechanisms of such very small particles will not be discussed in this review. Due to their small size, ENMs have unique properties (ie, optical, thermal, catalytic, and biological) compared to larger particles. ${ }^{5,6}$ During the last two decades, ENMs with tailored physicochemical properties have emerged in different fields of our daily life. They are used for a variety of applications, such as color pigments, solar cells, and waste water treatment. Furthermore, ENMs are found in consumer products that may be in contact with the human organism, eg, food packaging, shampoos, sunscreens, and toothpastes. Thus, regulatory agencies are faced with new materials for which no
Department of Pharmaceutical Sciences, Division of Pharmaceutical Technology, University of Basel, Klingelbergstrasse 50, 4056 Basel, Switzerland

Tel $+4|6| 267|5| 3$

Fax $+4 \mid 612671516$

Email joerg.huwyler@unibas.ch 
nano-specific safety standards have been established. Moreover, products containing ENMs are often not declared since formal requirements are lacking. ${ }^{5}$ The ingredients of ENMs tend to be listed as chemicals or micronized substances, and information about the ENMs' content in the product may be missing. Little is known on how ENMs interact with the environment, including animals and human beings. ${ }^{7}$ When used in a physiological environment, ENMs are faced with biological fluids, phospholipid membranes, clearing mechanisms, and harsh intracellular conditions. Due to their distinct physicochemical properties, ENMs interact in a different way with living cells as compared to dissolved molecules. It is a challenge to predict the mechanism of uptake in relation to one specific physicochemical property. Figure 1 highlights the differences between ENMs and small molecules with regard to their physical and chemical properties, cellular uptake mechanisms, intracellular fate, and toxic effects.

Small molecules are defined as compounds with a molecular weight of less than 1,000 Da. It is generally believed that lipophilic molecules below this threshold are able to penetrate cell membranes by passive diffusion. They have the potential to be taken up actively as well as passively by cells and to overcome cellular barriers within the body including the blood-brain barrier. ${ }^{8,9}$ In contrast, ENMs and macromolecules are mostly unable to diffuse passively into a living cell. They are colloidally dispersed and therefore require an active transport process for their uptake by target cells. ${ }^{10,11}$ Furthermore, ENMs are characterized by a high surface area to volume ratio as well as different geometries and surface characteristics. Particles of the same material can differ in shape, size, and porosity; whereas a molecule is a well-defined system. ${ }^{12}$ The state of dispersion and the variable size and shape of ENMs induces different uptake mechanisms for the same material.

The present review focuses on interactions of ENMs with biological systems on a cellular level (ie, mechanisms of cellular uptake and intracellular accumulation) and on the level of the whole organism (ie, circulation, distribution, and elimination). These interactions are a function of the intrinsic physicochemical properties of ENMs. An additional factor is protein binding. Protein adsorption onto the surface of an ENM leads to the formation of a protein corona and changes properties such as size or surface charge dramatically. ${ }^{13-15}$ We reviewed published experimental procedures since the

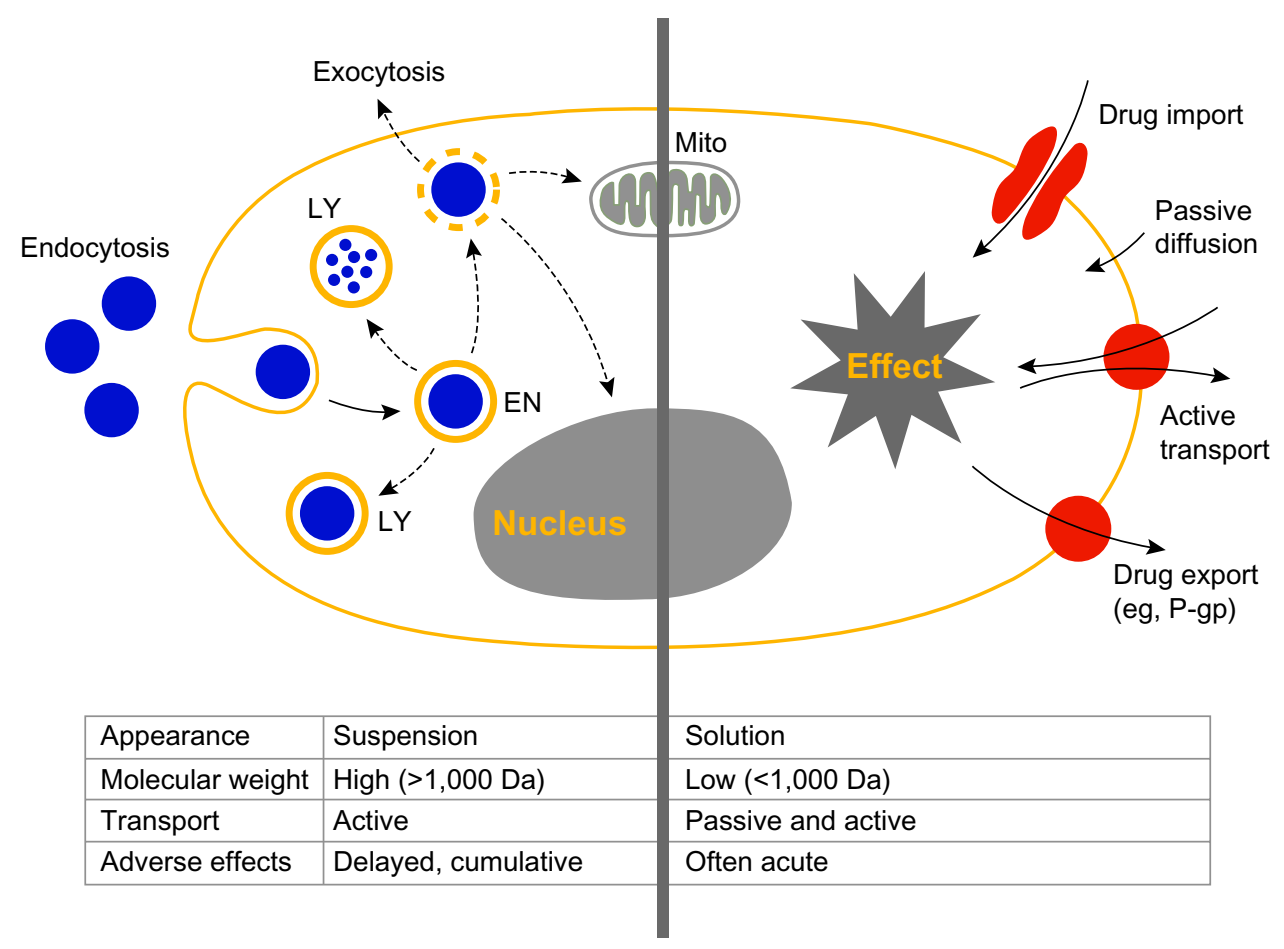

Figure I Interactions of cells with small molecules and nanoparticles.

Notes: Schematic representation of a eukaryotic cell and its interaction with nanoparticles (left part of picture) and small molecules (right part of picture). Interactions with nanoparticles are preceded by active cellular uptake leading to intracellular accumulation. Acute effects induced by small molecules are a consequence of both active and passive cell membrane permeation. Endocytosis leads to uptake of particles into endosomes (EN) and lysosomes (LY), followed by lysosomal degradation. Endosomal escape may lead to accumulation of particles in the cytoplasm or within mitochondria (Mito).

Abbreviations: EN, endosomes; LY, lysosomes; Mito, mitochondria; P-gP, P-glycoprotein. 
handling of ENMs is often a challenge, leading to statistical variability and artifacts.

\section{General considerations}

The state of dispersion of ENMs depends on their surface properties and the medium composition. Uptake studies should be performed with nonagglomerated ENMs. Agglomeration occurs by material interaction (ie, association of ENMs into clusters) or material-protein interaction. The resulting agglomerates sediment according to Stoke's law. The rate of agglomeration should be studied prior to in vitro uptake studies in the correspondent medium, for example, with dynamic light scattering (DLS). However, when complex biological media are involved (as in vivo), DLS is unsuited for studying agglomeration kinetics since blood components may interfere, fluorescence single particletracking (fSPT) may be an alternative method to be used under these conditions. ${ }^{16}$

Since the majority of ENM uptake studies use fluorescence as a tracking signal, it is crucial to minimize dye leakage from the ENM. ${ }^{10}$ Approaches to test dye leakage are centrifugation, sodiumdodecyl sulfate polyacrylamide gel electrophoresis (PAGE), or fluorescence correlation spectroscopy (FCS). ${ }^{17-19}$ Special care should be taken when choosing an appropriate dye since lipophilic dyes may partition from the particulate structure into the lipid membranes of the cell. To circumvent dye leakage, intrinsic fluorescence of nanoparticles is an attractive alternative, as has been described for gold. ${ }^{20,21}$

To study the entry route of a specific ENM, physical and pharmacological blockers may be used. All methods used to induce a physical or pharmacological block of uptake pathways have certain limitations. Most pharmacological inhibitors are not specific and may influence alternative internalization routes and the actin cytoskeleton. ${ }^{22}$ Pharmacological inhibitors interfere with vital cell functions and are therefore intrinsically toxic. Experiments have to be designed to prevent toxic effects, such as the complete disruption of all actin-dependent processes by actin-interfering agents. Moreover, compensatory routes of uptake may be activated in target cells upon inhibition of specific transport pathways. Finally, it should be taken into account that different cell lines have different uptake strategies. This impedes extrapolation of experimental results from one cell line to another. A recent review by Iversen et al summarizes the pharmacological blocking strategies and highlights the pitfalls of these reagents. ${ }^{23}$ It should be mentioned that genetically modified cells offer an interesting alternative to pharmacological intervention. ${ }^{24}$

\section{The influence of plasma protein binding on opsonization}

The properties of ENMs have the potential to modulate biological interactions between particles and target cells by different molecular mechanisms. ${ }^{6,25}$ Adsorption of biomolecules to surfaces influences the interactions at the nano-bio interface. ${ }^{26-28}$ In this way, bound proteins and biomolecules form a dynamic protein corona shaping the biological identity of the ENM. The composition of the protein corona varies over time due to continuous protein association and dissociation. ${ }^{29,30}$ Surface properties of ENMs will influence the composition of the protein corona. Hydrophobic ENMs easily adsorb proteins whereas hydrophilic ones are less prone to protein binding. ${ }^{31}$ Therefore, hydrophobic ENMs agglomerate readily and interact with other hydrophobic residues of proteins or peptides (eg, blood or membrane proteins), thus promoting internalization. ${ }^{30}$ Equally, positively charged ENMs adsorb different sets of proteins on their surface than negatively charged ones, elucidating distinct cellular interactions. ${ }^{32}$ This influences the mode of cell entry, biodistribution, and biocompatibility of ENMs. Interestingly, ENMs with identical chemical composition but different size may attract different proteins, thereby giving rise to different biological identities. ${ }^{33}$ An ENM in blood will have a different biological identity than the same ENM in body fluid and is therefore processed differently. The protein corona, in turn, modifies certain properties of the original ENM, such as surface charge and size. For example, highly positively charged nanoparticles with a positive zeta-potential may change their apparent charge to negative in cell-culture medium. ${ }^{34}$ These factors should be carefully considered when using ENMs as drug delivery devices, as the targeting ability of functionalized ENMs may be shielded by adsorbed proteins. ${ }^{35}$

\section{Cellular uptake of nanoparticles}

The phospholipid membrane of cells regulates the transport of molecules into the cells, thereby representing a universal barrier protecting fragile intracellular structures from extracellular materials (Figure 2). To enter the cell, polar or charged biomolecules, such as amino acids, nucleosides, or glucose, require active transport systems involving proteins or ion channels. Many macromolecules are actively taken up by cells via endocytosis, which is a vesicular transport mechanism. ${ }^{36,37}$ Because ENMs may exist in the size range 


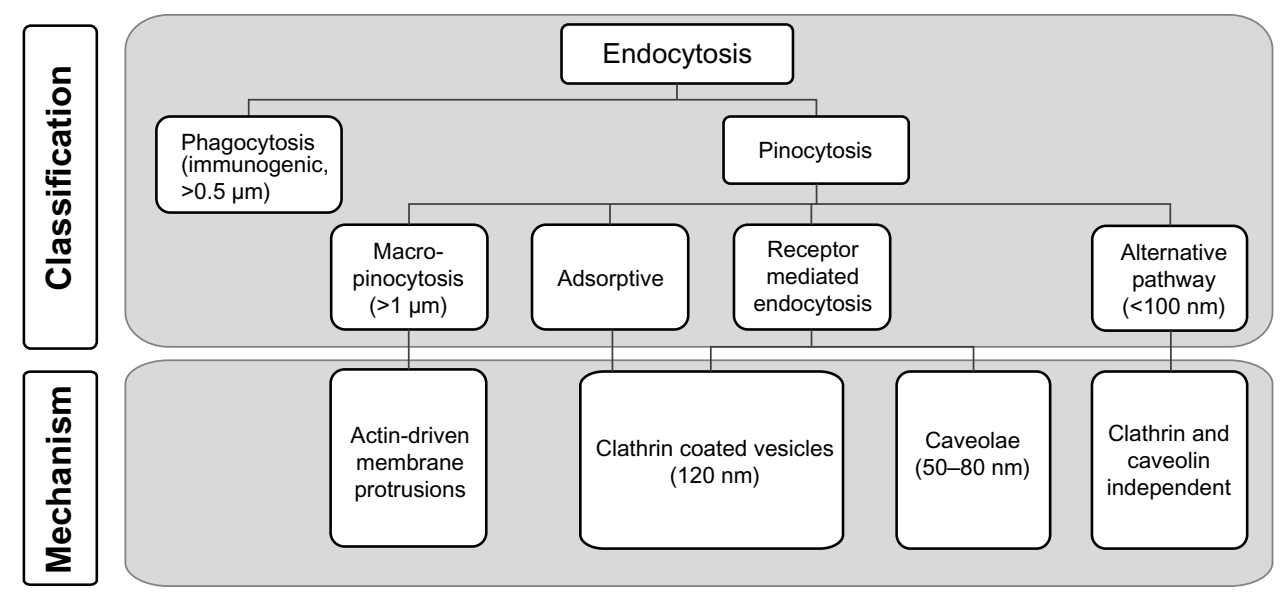

Figure 2 Known pathways of cellular uptake of nanoparticles.

Notes: Uptake of nanoparticles by eukaryotic cells is an active process. Endocytotic pathways include phagocytosis, and pinocytosis.

of proteins, eg, the hydrodynamic radius of an IgG antibody is close to $5 \mathrm{~nm},{ }^{38}$ they are able to interact with the cellular machinery in a similar way to macromolecules. ${ }^{10,25,26}$ Experimental studies revealed that most ENMs are actively incorporated into the cell via different endocytic pathways (Figure 2) comprising phagocytosis ("cell-eating") and pinocytosis ("cell-drinking"). The latter pathway can be divided into clathrin-mediated endocytosis (CME), caveolaemediated endocytosis (CvME), and alternative routes. . $^{39,40}$ The resulting transport vesicles differ with respect to the composition of the protein coat of the engulfed vesicle, size of the detached vesicle, and fate of the ingested cargo. ENMs have the potential to access cells by all entry portals depending on their size, shape, chemical composition, and surface modification. As stated above, it remains a challenge to correlate a given ENM property with an uptake route. In the following, we discuss the main cellular entry routes (ie, phagocytosis and pinocytosis) to establish a tentative link between nanoscale characteristics of ENMs and specific mechanisms of cellular uptake.

\section{Phagocytosis}

Phagocytosis is performed predominantly by specialized cells of the immune system (ie, macrophages, monocytes, neutrophils, and dendritic cells), to remove particles larger than $500 \mathrm{~nm}$ from the organism, mainly through the mode of a receptor-mediated process (Figure 2). ${ }^{41,42}$ Particles are recognized by small proteins (opsonins) including immunoglobulins type $\mathrm{G}$ or $\mathrm{M}$, complement fragments (C3, C5), or blood serum proteins such as fibronectin and laminin. ${ }^{43}$ This process promotes the specific binding of proteincoated particles to internalizing receptors on the cell plasma membrane, ie, Fc receptors of the immunoglobulin superfamily or complement receptors..$^{41}$ Other receptors involved in the uptake of ENMs are the mannose/fucose receptor ${ }^{44,45}$ as well as the scavenger receptor, ${ }^{46}$ where the involvement of the latter one may depend on the cell line used. The receptorligand interaction triggers a signal cascade in the target cell resulting in actin assembly and formation of a cell surface extension that zippers around the particle, engulfing it in an intracellular vesicle with a diameter of approximately 0.5 to $1 \mu \mathrm{m} .{ }^{42}$ These vesicles, or phagosomes, mature by several fission and fusion events with late endosomes and lysosomes, resulting in the formation of phagolysosomes. Internalized particles are subsequently degraded, and the receptors are cycled back to the cell surface. The rate of these successive events depends greatly on the ingested particle and typically lasts from 30 minutes to several hours. ${ }^{47}$ Although phagocytosis is generally thought to be involved in the uptake of larger particles, ie, particles sized $>500 \mathrm{~nm}$, recent reports document the phagocytic uptake of considerably smaller particles. ${ }^{48-50}$ The phagocytic uptake route seems to be rather unspecific since it depends on opsonization. ENMs taken up as agglomerate tend to be less easily degraded by the host as they can be detected in macrophages for several months, thus bearing a risk of long-term toxicity. ${ }^{51,52}$

\section{Pinocytosis}

Small particles ranging from a few nanometers to several hundred nanometers are generally taken up by pinocytosis (ie, fluid-phase uptake) occurring in almost all cell types (Figure 2). There are four modes of pinocytosis, ie, macropinocytosis, adsorptive and receptor-mediated endocytosis, and alternative routes of uptake. ${ }^{36}$ With macropinocytosis, large 
amounts of external fluid are taken up nonspecifically. ENMs located near the plasma membrane are thereby coincidentally internalized. During adsorptive pinocytosis, ENMs interact in a nonspecific manner with generic complementary binding sites on the cell surface. In contrast to macropinocytosis and adsorptive pinocytosis, RME is highly specific since it depends on the interaction between a ligand (eg, insulin or transferrin) and its complementary receptor on the surface of a target cell. RME is mediated predominantly either via the clathrin pathway or the caveolin pathway, depending on the specific nanoparticle-receptor interaction. ${ }^{23,53}$ Thus, several distinct pinocytic entry portals exist, depending on the type of interaction with the plasma membrane, size of incorporated vesicles, and type of proteins involved, eg, clathrin, caveolin, or receptors. ${ }^{36}$ Thereby, the size of endocytic vesicles of approximately $60 \mathrm{~nm}$ (caveolae) and $120 \mathrm{~nm}$ (clathrin-coated vesicles) imposes limitations with respect to the maximum size of ENMs entering these pathways. Different mechanisms of pinocytic uptake into cells are discussed in more detail below.

\section{Macropinocytosis}

During macropinocytosis, ENMs with a size of $>1 \mu \mathrm{m}$ are taken up nonspecifically. This process is stimulated, for example, by growth factors interacting with receptor tyrosine kinases. ${ }^{54}$ Activation of the signaling cascade results in the formation of actin-driven circular membrane protrusions that collapse onto the membrane and fuse with it. This generates uncoated endocytic vesicles with a size of $1 \mu \mathrm{m}$. These macropinosomes are of irregular shape and are handled by the endosomal/lysosomal route. ${ }^{36}$ Macropinocytosis contributes to the internalization of larger ENMs, albeit in a rather unspecific manner and often in conjunction with other entry mechanism. ${ }^{11,55}$ The capacity of this uptake pathway for ENMs is very high, suggesting a possibility for pharmaceutical delivery. ${ }^{56}$

\section{Clathrin-mediated endocytosis}

CME is considered to be the "classical" and best characterized route of cellular entry. ${ }^{37}$ In polarized cells such as endothelial or epithelial cells, transport is initialized at the apical membrane domain. ${ }^{36,57}$ ENMs with a size of 120-150 $\mathrm{nm}$ are internalized within clathrin-coated vesicles entering the endosomal/lysosomal trafficking route. ${ }^{58,59}$ The upper size limit reported for particles entering the cell via this pathway is $200 \mathrm{~nm} .{ }^{55} \mathrm{CME}$ is either adsorptive ${ }^{14}$ or receptor-mediated. ${ }^{60}$ Cationic particles or proteins bind nonspecifically to the negatively charged cell surface. ${ }^{61-63}$
This triggers adsorptive CME. In contrast, the receptormediated process is highly selective and specific. Receptor ligands being internalized by this pathway include lowdensity lipoprotein (LDL), transferrin, growth factors, and insulin. ${ }^{14}$

\section{Caveolin-mediated endocytosis}

CvME is the most prominent clathrin-independent uptake mechanism. This pathway is most pronounced in endothelial cells on the basolateral side, where it is an important uptake route for ENMs. ${ }^{36,64}$ The caveola is a small, flask-like structure, with a diameter of about 50-80 nm that is coated with caveolin-1. ${ }^{65}$ These vesicles invaginate with the help of dynamin from hydrophobic membrane domains, which are rich in cholesterol and glycosphingolipids. ${ }^{66}$ Caveolae are stable plasma membrane-associated structures. ${ }^{67,68}$ However, they can be induced to bud off by interaction with pathogens such as SV40 virus, ${ }^{69}$ cholera toxin subunit B, or Shiga toxin. ${ }^{70}$ With respect to ENMs, small particles seem to be transported more efficiently. For example, uptake of nanoparticles of 20 and $40 \mathrm{~nm}$ in size was demonstrated to be 5-10 times faster than that of nanoparticles sized $100 \mathrm{~nm} .{ }^{64,71}$ Larger particles (>500 nm) appear to be taken up only in exceptional cases. ${ }^{55}$ However, it is possible that ENM associating with the membrane may cover enough surface and colocalize by chance with certain markers like the caveolar marker. This does not mean that the uptake is actively dependent on caveolae.

The intracellular trafficking routes of caveolae are discussed controversially. While nonacidic, nondigestive pathways are favored, an additional link between caveolae and lysosomal routes for degradation cannot be excluded. ${ }^{65,70,72}$ In addition, the so-called caveosomes (previously supposed to represent a special type of caveolar endosome) were shown to be an artifact created by overexpression of caveolin or caveolin mutants. ${ }^{73}$ Pathogens escape from normal degradation in lysosomes and are directly transported to the Golgi and/or endoplasmic reticulum. ${ }^{74}$ Thus, pathogens and ENMs can bypass lysosomal degradation. ${ }^{75}$

\section{Alternative routes of uptake}

More recently, several endocytic routes that do not fit into the categories described above have emerged. Many of them are clathrin- and caveolin-independent. These routes depend on specific regulation by proteins such as Ras homolog family member A, ADP-ribosylation factor 6, or the cell division control protein 42 homolog, Cdc42. ${ }^{37,68}$ Although these mechanisms are still poorly understood, available data 
suggest that particles larger than $100 \mathrm{~nm}$ are internalized via these routes. ${ }^{66}$

\section{Characteristics of ENMs influencing cellular uptake}

The size of ENMs is not the only criterion that predicts the mechanism of ENM uptake. Nonetheless, trends based on particle size exist and are summarized in Figure 2. Nanoparticles with a diameter of $50 \mathrm{~nm}$ are more efficiently internalized by cells than smaller (about 15-30 nm) or larger (about 70-240 nm) particles. ${ }^{58,76}$ Nanoparticles with a diameter of 30-50 nm efficiently recruit and interact with membrane receptors and are subsequently taken up by receptor-mediated endocytosis. ${ }^{77}$

Besides size, ENM shape is an important factor. Spherical ENMs are taken up much faster and more efficiently than rod-shaped ENMs, presumably due to the longer membrane wrapping time required for the longer rod-shaped particles. $^{78,79}$ This notion is supported by in vivo experiments in rodents, where intravenous (IV)-injected elongated polymer micelles (filomicelles) remained in the circulation 10 times longer than spherical ENMs. ${ }^{80}$ However, controversial findings were obtained using different materials. For example, Gratton et $\mathrm{al}^{71}$ investigated hydrogel particle uptake into HeLa cells. The highest internalization rate was found for particles with an aspect ratio of three. ENMs seemed to use all internalization routes simultaneously. ${ }^{72}$ Recent findings suggest that silica rods with an aspect ratio of 2.1 to 2.5 are taken up to a higher extent into HeLa cells than their spherical counterparts. In addition, uptake of rods with higher aspect ratios was marginal. ${ }^{81}$ Tissue macrophages struggle to incorporate long and rigid fibers into phagosomes, thereby releasing harmful oxygen radicals and hydrolytic enzymes, causing chronic inflammation. ${ }^{82}$ Similarly, the needle-like structure of carbon nanotubes may penetrate biological membranes, inflicting mechanical damage. These controversial results suggest that additional factors promote cellular uptake besides ENM size and shape.

Surface functionalities (eg, surface charge and functional groups) mediate interactions between ENMs and the cell surface. Positively charged particles interact strongly with the slightly anionic plasma membrane. They are taken up more readily ${ }^{83}$ or may disrupt plasma membrane integrity. ${ }^{84}$ Positively charged ENMs are taken up via adsorptive mediated pinocytosis, whereas negatively charged ENMs use alternative uptake routes. ${ }^{85}$ Nonionic particles tend not to interact with the cell membrane, as demonstrated for the polymer polyethylene glycol (PEG) ${ }^{86}$ Nanoparticles can be functionalized with a plethora of ligands such as antibodies, peptides, or sugars. Their density, spatial distribution, and molecular weight plays an important role in determining the fate of ENMs in biological systems. ${ }^{87}$ In addition, the chain length of chemical linkers like PEG, which are used to attach ligands to the surface of nanoparticles, may affect delivery to target cells. ${ }^{88}$

Finally, specific cell types may interact with identical ENMs differently. ${ }^{23,89}$ It has been shown, for example, that macropinocytosis or phagocytosis is absent in brain capillary endothelial cells. ${ }^{8}$ Red blood cells are known to be incapable of endocytosis. Furthermore, recent studies revealed an influence of the cell cycle phase on the cell's capacity to take up ENMs. ${ }^{90}$

\section{Intracellular fate and endosomal escape}

Once ENMs have been taken up by target cells, they are directed to the endosomal/lysosomal pathway in most instances. The intracellular vesicles either gradually mature (acidify) to late endosomes through multiple fission and fusion events, or they are recycled back to the cellular surface as trafficking endosomes (Figure 1). ${ }^{91}$ ENMs entrapped in late endosomes are likely to proceed to lysosomes where they are degraded. These compartments harbor proteases, hydrolases, and other enzymes promoting ENM degradation. ${ }^{92}$ However, some ENMs (in particular positively charged, basic nanoparticles) are capable of escaping the endosome. This phenomenon has previously been described as the "proton sponge effect". ${ }^{25,93}$ Osmotic swelling of the organelles leads to their rupture, as shown in the case of polyethylene imine. ${ }^{93,94}$ To implement drug delivery strategies, endosomal/ lysosomal escape can be induced actively. $\mathrm{pH}$-sensitive fusiogenic liposomes, for example, contain synthetic sterols and phospholipids, which undergo phase transition upon protonation at low $\mathrm{pH}$. This results in the conversion of the hexagonal to lamellar structure of the liposomal membrane, thus disrupting the endosomal/lysosomal membrane. ${ }^{95-97}$ Similar effects can be induced using $\mathrm{pH}$-sensitive fusiogenic peptides (eg, amphiphilic peptides with repetitive GALA sequences) in combination with cationic liposomes. ${ }^{98}$ Other ENMs (eg, certain types of carbon nanotubes) penetrate the vesicle (or cell) membrane directly and enter the cytosol. ${ }^{99}$ Once in the cytosol, ENMs may induce the production of reactive oxygen species and inflict oxidative stress. ${ }^{100}$ In addition, potentially toxic interactions with other cellular organelles, such as mitochondria and the cell nucleus, may occur. $^{2}$ Effects that may be harmful for a healthy cell are 
desired in tumor cells, where an endosomal escape is needed to deliver a specific nanoparticulate drug to its intracellular compartment of action.

\section{Methods to determine nanoparticle uptake}

Widely used methods to study cellular uptake of ENMs are flow cytometry and microscopy. While flow cytometry allows for an efficient, fast, and quantitative assessment of particle uptake, microscopy provides qualitative insight into the subcellular localization of particles by analyzing small sample volumes. Flow cytometry as a quantitative approach to measure uptake cannot distinguish between externally attached and fully internalized ENM. Interaction with the cell surface can be studied experimentally if cellular uptake is inhibited. For example, endocytotic pathways can be blocked using pharmacological inhibitors. ${ }^{22,101}$ Alternatively, cells can be incubated at lowered temperatures to interrupt endocytic processing of particles. Temperatures around $20^{\circ} \mathrm{C}$ prevent progression of particles from early to late endosomes. ${ }^{102}$ Further temperature lowering to $4^{\circ} \mathrm{C}$, for example, blocks all energy-dependent processes. ${ }^{103}$ Consequently, signals from fluorescent ENMs located at the surface of cells or within specific intracellular vesicles or organelles can, for example, be detected quantitatively by flow cytometry or qualitatively by confocal scanning laser microscopy. ${ }^{104,105}$ Intracellular localization of particles can be further confirmed using the quenching agent, trypan blue. This dye quenches signals from fluorescent dyes such as fluorescein isothiocyanate. Since trypan blue does not penetrate the membrane, only extracellular signals of free or surface-bound dye molecules are quenched. ${ }^{106}$

Another quantitative approach is induced coupled plasma mass spectroscopy (ICP-MS). ICP-MS is a powerful tool for intracellular quantification of electron-dense materials and is a sensitive (ie, nanogram range) method for detecting elements with the exception of $\mathrm{H}, \mathrm{C}, \mathrm{O}, \mathrm{N}, \mathrm{F}, \mathrm{S}$, and inert gases. Due to this limitation, "soft" nanoparticles, such as liposomes, polymers, or dendrimers, are not detected. Additionally, ICP-MS is not able to distinguish between dissolved ions and nanoparticles. However, loading nanoparticles with a heavy metal may make the use of ICP-MS possible in such cases, as long as the physicochemical properties of the particles are not changed by the loading procedure. ${ }^{107}$

Alternatively, confocal microscopy provides information on the three-dimensional structure of objects. Fluorescence colocalization studies give insight into intracellular trafficking after fixation of cells or by live-cell imaging. The latter technique relies on highly photostable fluorophores but avoids artifacts introduced by fixation reagents such as paraformaldehyde. ${ }^{108}$ Subcellular fractionation can give additional insight into partitioning of ENMs inside the cell. Transmission electron microscopy is used to confirm subcellular particle localization with high resolution. This method allows quantitative assessments, but the procedure is time-consuming. ${ }^{109,110}$

It is advisable to use transmission electron microscopy in combination with energy-dispersive X-ray spectroscopy (EDX) to confirm the presence of nanoparticles. ${ }^{111}$ Brandenberger et al studied intracellular particle distribution using quantum dots as reference material. ${ }^{112}$ In this study, EDX was used to confirm the identity of quantum dots based on X-ray emission spectra of the elements $\mathrm{Cd}$ and $\mathrm{S}$. This method seems to be particularly useful for identifying very small $(5-10 \mathrm{~nm})$ particles. ${ }^{113}$

\section{The biological fate of ENMs}

In previous sections, we discussed interactions of ENMs with biological systems on a cellular level. This section focuses on in vivo kinetic properties of ENMs, addressing processes related to circulation, distribution, degradation, and excretion. There are different routes of administration including pulmonal, ${ }^{114}$ dermal, ${ }^{115,116}$ oral, ${ }^{117,118}$ and IV routes. ${ }^{119}$ However, this review will focus only on the IV route in healthy subjects. Figure 3 illustrates technical hurdles, challenges, and the different steps taken by ENMs before and during interaction with the living organism.

\section{Circulation of ENMs}

The state of dispersion in both the injected solution and the blood stream has to be defined, since agglomerates or precipitated material in the syringe may lead to dose variability (Figure 3A). Advanced pharmaceutical technologies are needed to stabilize nanosuspensions during storage and administration. ${ }^{120}$ Size is an important parameter regarding circulation and distribution within the organism. In the blood stream, agglomerates may cause embolism with a potentially fatal outcome. Agglomerated particles have a tendency to accumulate after IV administration within the lung since venous blood is directed from the right heart ventricle to this organ. In vivo studies in the rat using polystyrene particles demonstrated passive accumulation in the lung for particles with a size exceeding a threshold of $10 \mu \mathrm{m} .{ }^{121}$ Thus, findings of lung targeting of ENMs may be indicative of "accidental" trapping of agglomerates. ${ }^{122}$ As mentioned above, phagocytosis of ENMs is an additional 

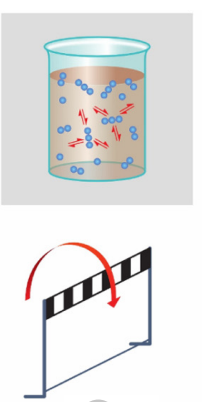

A

Agglomeration Deagglomeration Precipitation
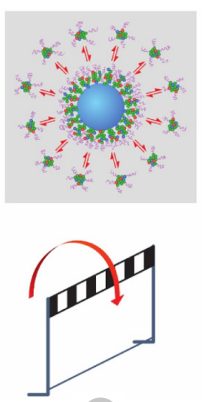

B

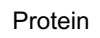
coating
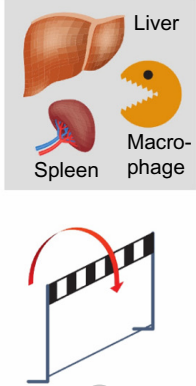

C

Elimination by MPS
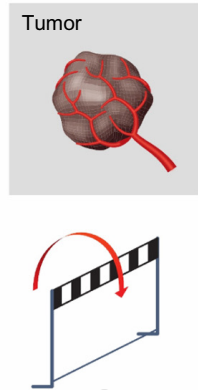

D

Accumulation at target site/ cellular uptake
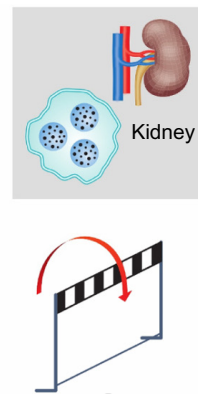

E

Biodegradation Elimination

Figure 3 Experimental challenges and hurdles.

Notes: Specific physicochemical properties of ENMs may lead to technical challenges and artifacts in experimental systems. Particle agglomeration (A) reduces dosing accuracy or may lead to embolism after IV injection. Plasma-protein binding and opsonization of nanoparticles (B) may trigger a humoral immune response. Interaction of nanoparticles with cells of the MPS leads to accelerated plasma clearance (C). Accumulation of particles at a defined target site (D) might be impeded by their premature degradation and elimination (E).

Abbreviations: ENMs, engineered nanomaterials; IV, intravenous; MPS, mononuclear phagocytic system.

factor limiting prolonged circulation of particles bigger than $0.5 \mu \mathrm{m}$ (Figure 2). On the other hand, small ENMs $(<5 \mathrm{~nm}$ to $10 \mathrm{~nm}$ ) are cleared by kidney glomerular filtration. ${ }^{123,124}$

\section{Opsonization and immunologic responses}

When injected into the blood stream, foreign materials encounter different blood constituents such as red blood cells, white blood cells, platelets, and a variety of proteins. ENMs are known to interact with both proteins ${ }^{26}$ and cells. ${ }^{125}$ Protein binding and opsonization are processes that change the surface properties of ENMs (Figure 3B). ENMs used for imaging or as a drug delivery system should be assessed with regard to their potential to cause hemolysis, thrombocyte aggregation, and complement activation. ${ }^{47,126}$ Hemolysis has been described for rigid materials such as silica nanoparticles ${ }^{127}$ or for soft nanoparticles such as liposomes. ${ }^{128}$ Due to protein binding, these measurements should be done in presence of plasma proteins. ${ }^{129}$

Protein coating of an ENM is a highly dynamic process, starting immediately upon IV injection. ${ }^{130}$ The resulting protein corona is complex and varies depending on the size, ${ }^{13}$ hydrophobicity/surface charge, ${ }^{30}$ and shape ${ }^{131}$ of the particles. In the first instance, readily available proteins such as albumin are adsorbed onto the ENM surface, but may be replaced by other proteins (eg, lipoproteins or opsonins) over time, depending on the surface structure of the ENMs. Prediction of the extent of protein binding to ENM remains a challenge. Recent findings indicate that uncharged ENMs are opsonized more slowly than charged ENMs. The size of ENMs influences the binding of opsonins to spherical particles. Due to the higher curvature, smaller ENMs $(<20 \mathrm{~nm})$ will attract fewer opsonins than bigger ENMs ( $>200 \mathrm{~nm})$. This explains why agglomerates are cleared by the mononuclear phagocytic system (MPS) more easily. The same is true for hydrophobic ENMs. ${ }^{132}$ Recent studies revealed a strong shape dependency in relation with MPS recognition. Duan and $\mathrm{Li}^{133}$ stated that an ellipsoidal ENM can be attacked by a macrophage in two different ways: when the macrophage attaches to the pointed end, the ENM will be internalized; however, when it attaches on the flat surface of the ellipsoid, it just spreads on the ENM and prolongs its circulation. This observation is in agreement with the findings of Arnida et al who found that gold nanorods were less recognized by the MPS compared to their spherical counterparts. ${ }^{134}$

The question arises as to how ENMs can be designed to specifically adsorb certain proteins or avoid their adsorption. The best known strategy to diminish protein adsorption is by masking the particle surface with PEG. This hydrophilic, biocompatible, and nontoxic polymer is used to minimize interactions of macromolecules, eg, cytokines ${ }^{135}$ and nanoparticles, ie, liposomal carriers ${ }^{101}$ with phagocytic cells of the immune system. The protective properties of PEG as a function of PEG chain length and PEG surface density were reviewed by Li and Huang. ${ }^{136}$ Nevertheless, PEG is not able to fully prevent protein adsorption or opsonization. For example, for $5 \mathrm{~nm}$ gold nanoparticles, the protective effect of PEG diminishes within hours. ${ }^{137}$ In addition, PEG may elicit an immunological response resulting in an accelerated blood clearance of ENMs. It has been observed that repeatedly injected PEGylated liposomal formulations are markedly less efficacious, probably because of anti-PEG antibody formation. ${ }^{138}$ As an alternative to PEGylation, ENMs can be 
coated with amino acids such as lysine or cysteine. Such a mixed-charge monolayer-coating prevented protein adsorption in fetal bovine serum to $5 \mathrm{~nm}$ gold nanoparticles. ${ }^{139} \mathrm{In}$ summary, a hydrophilic coating (eg, PEG) and a neutral charge (expressed as the zeta potential in the correspondent medium) can minimize particle recognition by the immune system. Targeting strategies are often implemented using PEG-coated ENMs with surface ligands (such as folic acid, cell adhesion molecules, or transferrin ${ }^{42}$ ) in order to enhance cellular uptake into target tissues and to avoid exposure of healthy cells. By this approach, it is crucial to maintain the stealth properties of the PEG, despite the bound ligands, to avoid interactions with cells of the immune system. ${ }^{101}$

\section{Distribution}

ENMs are distributed throughout the body via the blood stream and extravasate this transport system according to their size. Extravasation of ENMs is restricted to specific tissues since the presence of tight junctions prevents ENMs larger than $2 \mathrm{~nm}$ to leave the circulation. ${ }^{140}$ The fenestrations of blood vessels vary from organ to organ and can have different ranges in different species. ${ }^{140}$ Moreover, the state of disease is changing the fenestration size, ${ }^{141}$ with typical size for tumors ranging from $200-780 \mathrm{~nm}$ in mice. ${ }^{142}$ ENMs with sizes ranging from 150-300 $\mathrm{nm}$ are mainly found in the liver and spleen, whereas smaller counterparts extravasate into the bone marrow. ENMs are cleared from the circulation in different organs. As depicted in Figure 3C, they are often trapped in the liver and spleen as these organs host the largest concentration of tissue resident macrophages (ie, MPS cells such as hepatic Kupffer cells). Glomerular filtration eliminates ENMs with a hydrodynamic diameter of $<5 \mathrm{~nm}$ to $10 \mathrm{~nm}$. Nonetheless, the relationship between the physicochemical properties and pharmacokinetic behavior of ENMs is poorly understood. Interpretation of experimental data is difficult since a plethora of different materials, excipients, and animal species are used. However, trends were identified for selected materials such as gold nanoparticles of different sizes and surface characteristics. ${ }^{143,144}$ Increased liver accumulation was found for particles with a size of $\geq 5 \mathrm{~nm}$ as compared to particles with a size of $1.4 \mathrm{~nm}$. Particle sizedependent accumulation was found in no other organ than the liver. However, elevated levels of charged (positive and negative) gold nanoparticles were found in the spleen. In another study, PEG-coated gold nanoparticles with a size of 20-80 nm were investigated. ${ }^{145}$ The length of the PEG chains was 2,000-5,000 Da. PEGylated gold nanoparticles were not recognized by macrophages. The PEG-5,000 coated gold particles with a size of $20 \mathrm{~nm}$ accumulated in solid tumors of experimental animals to an extent of $6.5 \%$ of the injected dose. Most of the remaining particles accumulated in other organs, mainly liver and spleen. Xie et al investigated the influence of the size of silica nanoparticles on their biodistribution. ${ }^{146}$ After 30 days, they found silica particles trapped in the lungs, liver, and spleen and observed signs of liver injury. Compared to small silica particles $(20 \mathrm{~nm})$, larger particles $(80 \mathrm{~nm})$ were cleared faster from the body. A recent study investigated the difference in biodistribution of solid silica nanoparticles, mesoporous silica nanoparticles, and rod-shaped silica nanoparticles. ${ }^{147}$ All particle types had a positively charged surface and showed extensive distribution to liver and spleen. Thus, most particles were recognized and eliminated by phagocytic macrophages. Porous particles with an aspect ratio of eight preferentially accumulated in the lung, whereas the nonporous particles were less prevalent in the lung. Amine modified silica nanoparticles reduced the affinity to lungs and kidneys. Silica nanoparticles were degraded and excreted via the hepatobiliary and renal routes. It has been reported that elongated fibers such as filomicelles ${ }^{80}$ or gold nanorods ${ }^{134}$ display a longer circulation time since they are able to align with the blood flow. Compared to their spherical counterparts, rods are less preferentially taken up by macrophages, which reduce accumulation in MPS organs like the liver and spleen. Furthermore, gold nanorods had a higher accumulation in tumor tissue compared to spherical gold nanoparticles. ${ }^{134}$

ENMs can be designed in a way to promote or avoid interactions with specific tissues or organs. The topic of active drug targeting was recently reviewed by Moghimi et al. ${ }^{148}$ With such targeting strategies, ENMs can be designed and used for diagnostic imaging purposes or to deliver drugs to diseased tissues such as solid tumors (Figure 3D). The passive accumulation in the tumor is due to the enhanced permeability and retention effect, which is present in some tumors and dictates the maximum size for ENMs to extravasate into tumor tissue. This phenomenon is discussed in more detail by Jain. ${ }^{149}$

\section{Degradation and excretion}

The term "metabolism" as defined in classical pharmacokinetics is not suitable for ENMs. In this section, the term "degradation" will be used instead to collectively cover multiple processes such as erosion, deagglomeration, disintegration, dissolution, or chemical degradation of particles. Available excretion and degradation studies solely included single administration of ENMs at a certain concentration. 


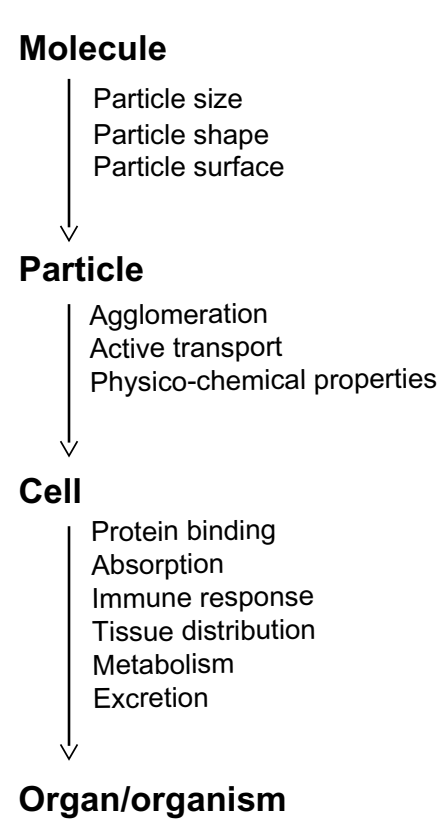

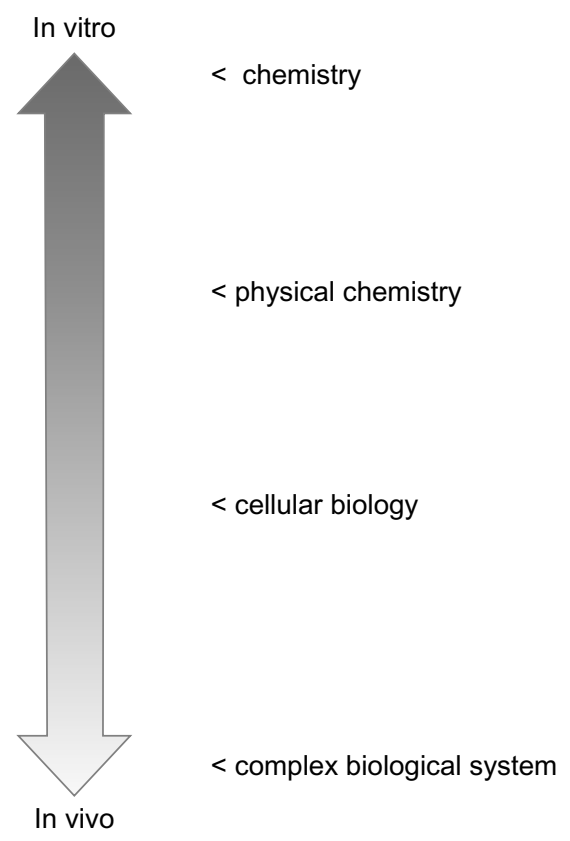

Figure 4 Extrapolation from in vitro data to the in vivo situation.

Notes: In vitro experimental systems can be used to characterize nanoparticles with respect to their chemical composition and physicochemical properties. Cell-culturebased experimental systems can be used to study molecular mechanisms of cellular uptake and intracellular processing of particles. However, additional information is needed to address questions related to the in vivo behavior of nanomaterials and their interaction with complex biological systems. In particular, the prediction of pharmacokinetic parameters remains a challenge.

Accumulation effects after multiple dosing and bioaccumulation have only been studied in zebra fish. ${ }^{150}$ Chemical reactivity and composition of the shell and core materials play an important role in degradation. ENMs known to "safely" degrade are porous silica nanoparticles ${ }^{20}$ and iron oxide particles. ${ }^{151}$ Degradation of silica nanoparticles leads to the formation of silicic acid, which is excreted via feces and urine. ${ }^{152}$ Due to the high specific surface area of the mesoporous material, hydrolysis of the silica network is a fast process. ${ }^{153}$ Metal oxides including iron oxides are transformed by metallothionein that is abundantly expressed in liver and kidney. ${ }^{154}$ Levy et al used two different methods to trace biodegradation of super paramagnetic iron oxide nanoparticles (SPIONs). ${ }^{155}$ Upon degradation, these iron species lose their paramagnetic behavior and are transformed to ferritin. Thus, intact particles can be identified and traced due to their magnetic properties. However, degradation is a slow process. After two months, paramagnetic iron was still present in macrophages. Over prolonged time, the storage form of iron (ie, nonparamagnetic species) was more prevalent. The authors hypothesized that degradation of SPIONs took place in the acidic lysosomal compartment. It remains to be elucidated if these mechanisms of degradation might apply to other nanomaterials including other metal oxide materials with poor solubility. ENMs, like polymeric particles, have been shown to degrade by hydrolysis or enzymatic digestion in vitro. ${ }^{156}$ Similar effects were observed in vivo. ${ }^{157}$

Materials with poor solubility may remain in the organism over several weeks to months. When considering the use of a specific ENM as a drug delivery tool, its biodegradation and excretion pathways have to be known. Upon multiple dosing, ENMs may accumulate in MPS organs and cause severe damage. For example, Ye et al have studied long-term effects of quantum dots containing Cd-Se in rhesus monkeys. ${ }^{158} \mathrm{In}$ vivo, acute toxicity of theses nanoparticles was very low. However, chemical analysis after 90 days revealed that more than $90 \%$ of the injected Cd dose remained in the animals' organs. In view of the limited availability of data, much more work needs to be done in the field of nanosafety.

\section{Conclusion}

ENMs have emerged in different fields of our daily life. However, their interaction with biological systems and their biological fate remain incompletely understood. It is therefore important to elucidate molecular mechanisms involved in cellular binding, uptake, and processing of ENMs. This knowledge is needed to design novel pharmaceutical applications for ENMs such as, for example, drug delivery and drug targeting strategies. By the same token, optimized ENM design may help to avoid unwanted interactions and toxicity, thereby making human use of novel materials possible. 
The interaction of ENMs with complex biological systems, such as the human body, is still poorly understood. In vitro characterization of ENMs may help to obtain a mechanistic insight into their behavior in a biological environment (Figure 4). This includes information on chemical properties and reactivity as well as particle dynamics in biological fluids. Studies have shown that protein binding may alter the properties of ENM surfaces influencing cellular binding and uptake. Interactions with the immune system depend on ENM size, geometry, and surface charge. However, this information cannot be easily extrapolated to any given cell line or even to another ENM with the same surface properties but different core materials. We propose to combine in vitro systems with ex vivo models such as lung models, ${ }^{159}$ cell coculture systems, chicken egg models harboring xenografted tumors, ${ }^{50}$ and placenta models. ${ }^{3}$ These tools will be instrumental when designing nanomaterials with favorable pharmacokinetic properties and low intrinsic toxicity. ${ }^{160}$ In any case, ENMs should be designed to be biocompatible and biodegradable to prevent their accumulation in the human body and limit their long-term toxic effects upon chronic exposure. Combining this knowledge about ENMs with smart drug delivery and drug targeting strategies will lead to innovative diagnostic and therapeutic applications.

\section{Acknowledgments}

The present work was supported by grants from the "Freie Akademische Gesellschaft (FAG) Basel" and the Swiss Centre for Applied Human Toxicology (SCAHT). We thank Dr Silvia Rogers for editorial assistance.

\section{Disclosure}

The authors report no conflicts of interest in this work.

\section{References}

1. Bleeker EA, de Jong WH, Geertsma RE, et al. Considerations on the EU definition of a nanomaterial: science to support policy making. Regul Toxicol Pharmacol. 2013;65(1):119-125.

2. Rothen-Rutishauser B, Mühlfeld C, Blank F, Musso C, Gehr P. Translocation of particles and inflammatory responses after exposure to fine particles and nanoparticles in an epithelial airway model. Part Fibre Toxicol. 2007;4:9.

3. Wick P, Malek A, Manser P, et al. Barrier capacity of human placenta for nanosized materials. Environ Health Perspect. 2010;118(3):432-436.

4. Chang HI, Yeh M-K. Clinical development of liposome-based drugs: formulation, characterization, and therapeutic efficacy. Int $J$ Nanomedicine. 2012;7:49-60.

5. Kessler R. Engineered nanoparticles in consumer products: understanding a new ingredient. Environ Health Perspect. 2011;119(3):a120-a125.

6. Oberdörster G, Maynard A, Donaldson K, et al. Principles for characterizing the potential human health effects from exposure to nanomaterials: elements of a screening strategy. Part Fibre Toxicol. $2005 ; 2: 8$.
7. Som C, Wick P, Krug H, Nowack B. Environmental and health effects of nanomaterials in nanotextiles and façade coatings. Environ Int. 2011;37(6):1131-1142.

8. Pardridge WM. Transport of small molecules through the blood-brain barrier: biology and methodology. Adv Drug Deliv Rev. 1995;15(1-3): 5-36.

9. Pardridge WM. Drug transport across the blood-brain barrier. J Cereb Blood Flow Metab. 2012;32(11):1959-1972.

10. Salvati A, Aberg C, dos Santos T, et al. Experimental and theoretical comparison of intracellular import of polymeric nanoparticles and small molecules: toward models of uptake kinetics. Nanomedicine. 2011;7(6): $818-826$.

11. Shapero K, Fenaroli F, Lynch I, Cottell DC, Salvati A, Dawson KA Time and space resolved uptake study of silica nanoparticles by human cells. Mol Biosyst. 2011;7(2):371-378.

12. Krug HF, Wick P. Nanotoxicology: an interdisciplinary challenge. Angew Chem Int Ed Engl. 2011;50(6):1260-1278.

13. Jansch M, Stumpf P, Graf C, Rühl E, Müller RH. Adsorption kinetics of plasma proteins on ultrasmall superparamagnetic iron oxide (USPIO) nanoparticles. Int J Pharm. 2012;428(1-2):125-133.

14. Lesniak A, Campbell A, Monopoli MP, Lynch I, Salvati A, Dawson KA. Serum heat inactivation affects protein corona composition and nanoparticle uptake. Biomaterials. 2010;31(36):9511-9518.

15. Monopoli MP, Aberg C, Salvati A, Dawson KA. Biomolecular coronas provide the biological identity of nanosized materials. Nat Nanotechnol. 2012;7(12):779-786.

16. Filipe V, Poole R, Kutscher M, Forier K, Braeckmans K, Jiskoot W. Fluorescence single particle tracking for the characterization of submicron protein aggregates in biological fluids and complex formulations. Pharm Res. 2011;28(5):1112-1120.

17. Magde D, Elson E, Webb WW. Thermodynamic Fluctuations in a Reacting System - Measurement by Fluorescence Correlation Spectroscopy. Phys Rev Lett. 1972;29(11):705-708.

18. Onaca O, Hughes DW, Balasubramanian V, Grzelakowski M, Meier W, Palivan CG. SOD antioxidant nanoreactors: influence of block copolymer composition on the nanoreactor efficiency. Macromol Biosci. 2010;10(5):531-538.

19. Ow H, Larson DR, Srivastava M, Baird BA, Webb WW, Wiesner U. Bright and stable core-shell fluorescent silica nanoparticles. Nano Lett. 2004;5(1):113-117.

20. He X, Nie H, Wang K, Tan W, Wu X, Zhang P. In vivo study of biodistribution and urinary excretion of surface-modified silica nanoparticles. Anal Chem. 2008;80(24):9597-9603.

21. Lemelle A, Veksler B, Kozhevnikov IS, Akchurin GG, Piletsky SA, Meglinski I. Application of gold nanoparticles as contrast agents in confocal laser scanning microscopy. Laser Phys Lett. 2009;6(1):71-75.

22. Ivanov AI. Pharmacological inhibition of endocytic pathways: is it specific enough to be useful? Methods Mol Biol. 2008;440:15-33.

23. Iversen TG, Skotland T, Sandvig K. Endocytosis and intracellular transport of nanoparticles: Present knowledge and need for future studies. Nano Today. 2011;6(2):176-185.

24. Smith PJ, Giroud M, Wiggins HL, et al. Cellular entry of nanoparticles via serum sensitive clathrin-mediated endocytosis, and plasma membrane permeabilization. Int J Nanomedicine. 2012;7:2045-2055.

25. Nel AE, Mädler L, Velegol D, et al. Understanding biophysicochemical interactions at the nano-bio interface. Nat Mater. 2009;8(7):543-557.

26. Aggarwal P, Hall JB, McLeland CB, Dobrovolskaia MA, McNeil SE. Nanoparticle interaction with plasma proteins as it relates to particle biodistribution, biocompatibility and therapeutic efficacy. Adv Drug Deliv Rev. 2009;61(6):428-437.

27. Wang T, Bai J, Jiang X, Nienhaus GU. Cellular uptake of nanoparticles by membrane penetration: a study combining confocal microscopy with FTIR spectroelectrochemistry. ACS Nano. 2012;6(2):1251-1259.

28. Prapainop K, Witter DP, Wentworth P Jr. A chemical approach for cell-specific targeting of nanomaterials: small-molecule-initiated misfolding of nanoparticle corona proteins. J Am Chem Soc. 2012;134(9): 4100-4103. 
29. Darabi Sahneh F, Scoglio C, Riviere J. Dynamics of nanoparticle-protein corona complex formation: analytical results from population balance equations. PLoS ONE. 2013;8(5):e64690.

30. Cedervall T, Lynch I, Lindman S, et al. Understanding the nanoparticleprotein corona using methods to quantify exchange rates and affinities of proteins for nanoparticles. Proc Natl Acad Sci U S A. 2007;104(7): 2050-2055.

31. Esmaeili F, Ghahremani MH, Esmaeili B, Khoshayand MR, Atyabi F, Dinarvand R. PLGA nanoparticles of different surface properties: preparation and evaluation of their body distribution. Int $J$ Pharm. 2008;349(1-2):249-255.

32. Fleischer CC, Payne CK. Nanoparticle surface charge mediates the cellular receptors used by protein-nanoparticle complexes. $J$ Phys Chem B. 2012;116(30):8901-8907.

33. Zhang H, Burnum KE, Luna ML, et al. Quantitative proteomics analysis of adsorbed plasma proteins classifies nanoparticles with different surface properties and size. Proteomics. 2011;11(23):4569-4577.

34. Limbach LK, Wick P, Manser P, Grass RN, Bruinink A, Stark WJ. Exposure of engineered nanoparticles to human lung epithelial cells: influence of chemical composition and catalytic activity on oxidative stress. Environ Sci Technol. 2007;41(11):4158-4163.

35. Salvati A, Pitek AS, Monopoli MP, et al. Transferrin-functionalized nanoparticles lose their targeting capabilities when a biomolecule corona adsorbs on the surface. Nat Nanotechnol. 2013;8(2):137-143.

36. Conner SD, Schmid SL. Regulated portals of entry into the cell. Nature. 2003;422(6927):37-44.

37. Kumari S, Mg S, Mayor S. Endocytosis unplugged: multiple ways to enter the cell. Cell Res. 2010;20(3):256-275.

38. Jøssang T, Feder J, Rosenqvist E. Photon correlation spectroscopy of human IgG. J Protein Chem. 1988;7(2):165-171.

39. Lühmann T, Rimann M, Bittermann AG, Hall H. Cellular uptake and intracellular pathways of PLL-g-PEG-DNA nanoparticles. Bioconjug Chem. 2008;19(9):1907-1916.

40. Mailänder V, Landfester K. Interaction of nanoparticles with cells. Biomacromolecules. 2009;10(9):2379-2400.

41. Aderem A, Underhill DM. Mechanisms of phagocytosis in macrophages. Annu Rev Immunol. 1999;17:593-623.

42. Hillaireau H, Couvreur P. Nanocarriers' entry into the cell: relevance to drug delivery. Cell Mol Life Sci. 2009;66(17):2873-2896.

43. Owens DE 3rd, Peppas NA. Opsonization, biodistribution, and pharmacokinetics of polymeric nanoparticles. Int J Pharm. 2006;307(1): 93-102.

44. Irache JM, Salman HH, Gamazo C, Espuelas S. Mannose-targeted systems for the delivery of therapeutics. Expert Opin Drug Deliv. 2008;5(6):703-724.

45. Patel PC, Giljohann DA, Daniel WL, Zheng D, Prigodich AE, Mirkin CA. Scavenger receptors mediate cellular uptake of polyvalent oligonucleotide-functionalized gold nanoparticles. Bioconjug Chem. 2010;21(12):2250-2256.

46. Wang $\mathrm{H}, \mathrm{Wu} \mathrm{L}$, Reinhard BM. Scavenger receptor mediated endocytosis of silver nanoparticles into J774A.1 macrophages is heterogeneous. ACS Nano. 2012;6(8):7122-7132.

47. Dobrovolskaia MA, McNeil SE. Immunological properties of engineered nanomaterials. Nat Nanotechnol. 2007;2(8):469-478.

48. França A, Aggarwal P, Barsov EV, Kozlov SV, Dobrovolskaia MA, González-Fernández Á. Macrophage scavenger receptor A mediates the uptake of gold colloids by macrophages in vitro. Nanomedicine (Lond). 2011;6(7):1175-1188.

49. Krpetić Z, Porta F, Caneva E, Dal Santo V, Scarì G. Phagocytosis of biocompatible gold nanoparticles. Langmuir. 2010;26(18):14799-14805.

50. Lunov O, Syrovets T, Loos C, et al. Differential uptake of functionalized polystyrene nanoparticles by human macrophages and a monocytic cell line. ACS Nano. 2011;5(3):1657-1669.

51. Wang X, Xia T, Ntim SA, et al. Dispersal state of multiwalled carbon nanotubes elicits profibrogenic cellular responses that correlate with fibrogenesis biomarkers and fibrosis in the murine lung. ACS Nano. 2011;5(12):9772-9787.
52. Zhu MT, Feng WY, Wang Y, et al. Particokinetics and extrapulmonary translocation of intratracheally instilled ferric oxide nanoparticles in rats and the potential health risk assessment. Toxicol Sci. 2009;107(2): 342-351.

53. Vercauteren D, Rejman J, Martens TF, Demeester J, De Smedt SC, Braeckmans K. On the cellular processing of non-viral nanomedicines for nucleic acid delivery: mechanisms and methods. J Control Release. 2012;161(2):566-581

54. Mercer J, Helenius A. Virus entry by macropinocytosis. Nat Cell Biol. 2009;11(5):510-520

55. Rejman J, Oberle V, Zuhorn IS, Hoekstra D. Size-dependent internalization of particles via the pathways of clathrin- and caveolaemediated endocytosis. Biochem J. 2004;377(Pt 1):159-169.

56. Rima W, Sancey L, Aloy M-T, et al. Internalization pathways into cancer cells of gadolinium-based radiosensitizing nanoparticles. Biomaterials. 2013;34(1):181-195.

57. Sandvig K, Pust S, Skotland T, van Deurs B. Clathrin-independent endocytosis: mechanisms and function. Curr Opin Cell Biol. 2011;23(4): 413-420.

58. Chithrani BD, Ghazani AA, Chan WCW. Determining the size and shape dependence of gold nanoparticle uptake into mammalian cells. Nano Lett. 2006;6(4):662-668.

59. Harush-Frenkel O, Rozentur E, Benita S, Altschuler Y. Surface charge of nanoparticles determines their endocytic and transcytotic pathway in polarized MDCK cells. Biomacromolecules. 2008;9(2):435-443.

60. Bickel U, Yoshikawa T, Pardridge WM. Delivery of peptides and proteins through the blood-brain barrier. Adv Drug Deliv Rev. 2001;46(1-3):247-279.

61. Herve F, Ghinea N, Scherrmann J-M. CNS delivery via adsorptive transcytosis. AAPS J. 2008;10(3):455-472.

62. Predescu SA, Predescu DN, Malik AB. Molecular determinants of endothelial transcytosis and their role in endothelial permeability. Am J Physiol Lung Cell Mol Physiol. 2007;293(4):L823-L842.

63. Thomsen LB, Lichota J, Eskehave TN, et al. Brain delivery systems via mechanism independent of receptor-mediated endocytosis and adsorptive-mediated endocytosis. Curr Pharm Biotechnol. 2012;13(12): 2349-2354.

64. Wang Z, Tiruppathi C, Minshall RD, Malik AB. Size and dynamics of caveolae studied using nanoparticles in living endothelial cells. ACS Nano. 2009;3(12):4110-4116.

65. Parton RG, Simons K. The multiple faces of caveolae. Nat Rev Mol Cell Biol. 2007;8(3):185-194.

66. Mayor S, Pagano RE. Pathways of clathrin-independent endocytosis. Nat Rev Mol Cell Biol. 2007;8(8):603-612.

67. Hommelgaard AM, Roepstorff K, Vilhardt F, Torgersen ML, Sandvig K, van Deurs B. Caveolae: stable membrane domains with a potential for internalization. Traffic. 2005;6(9):720-724.

68. Howes MT, Kirkham M, Riches J, et al. Clathrin-independent carriers form a high capacity endocytic sorting system at the leading edge of migrating cells. J Cell Biol. 2010;190(4):675-691.

69. Pelkmans L, Püntener D, Helenius A. Local actin polymerization and dynamin recruitment in SV40-induced internalization of caveolae. Science. 2002;296(5567):535-539.

70. Hayer A, Stoeber M, Ritz D, Engel S, Meyer HH, Helenius A. Caveolin-1 is ubiquitinated and targeted to intralumenal vesicles in endolysosomes for degradation. J Cell Biol. 2010;191(3):615-629.

71. Gratton SE, Ropp PA, Pohlhaus PD, et al. The effect of particle design on cellular internalization pathways. Proc Natl Acad Sci U SA. 2008;105(33):11613-11618.

72. Pelkmans L, Bürli T, Zerial M, Helenius A. Caveolin-stabilized membrane domains as multifunctional transport and sorting devices in endocytic membrane traffic. Cell. 2004;118(6):767-780.

73. Parton RG, Howes MT. Revisiting caveolin trafficking: the end of the caveosome. J Cell Biol. 2010;191(3):439-441.

74. Bengali Z, Rea JC, Shea LD. Gene expression and internalization following vector adsorption to immobilized proteins: dependence on protein identity and density. $J$ Gene Med. 2007;9(8):668-678. 
75. Rejman J, Conese M, Hoekstra D. Gene transfer by means of lipoand polyplexes: role of clathrin and caveolae-mediated endocytosis. J Liposome Res. 2006;16(3):237-247.

76. Lu F, Wu SH, Hung Y, Mou CY. Size effect on cell uptake in wellsuspended, uniform mesoporous silica nanoparticles. Small. 2009;5(12): 1408-1413.

77. Albanese A, Tang PS, Chan WC. The effect of nanoparticle size, shape, and surface chemistry on biological systems. Annu Rev Biomed Eng. 2012;14:1-16.

78. Champion JA, Katare YK, Mitragotri S. Particle shape: a new design parameter for micro- and nanoscale drug delivery carriers. J Control Release. 2007;121(1-2):3-9.

79. Ferrari M. Nanogeometry: beyond drug delivery. Nat Nanotechnol. 2008;3(3):131-132.

80. Geng Y, Dalhaimer P, Cai S, et al. Shape effects of filaments versus spherical particles in flow and drug delivery. Nat Nanotechnol. 2007;2(4):249-255.

81. Meng H, Yang S, Li Z, et al. Aspect ratio determines the quantity of mesoporous silica nanoparticle uptake by a small GTPase-dependent macropinocytosis mechanism. ACS Nano. 2011;5(6):4434-4447.

82. Donaldson K, Murphy FA, Duffin R, Poland CA. Asbestos, carbon nanotubes and the pleural mesothelium: a review of the hypothesis regarding the role of long fibre retention in the parietal pleura, inflammation and mesothelioma. Part Fibre Toxicol. 2010;7:5.

83. Qiu Y, Liu Y, Wang L, et al. Surface chemistry and aspect ratio mediated cellular uptake of Au nanorods. Biomaterials. 2010;31(30):7606-7619.

84. Lovrić J, Bazzi HS, Cuie Y, Fortin GRA, Winnik FM, Maysinger D. Differences in subcellular distribution and toxicity of green and red emitting CdTe quantum dots. J Mol Med. 2005;83(5):377-385.

85. Dausend J, Musyanovych A, Dass M, et al. Uptake mechanism of oppositely charged fluorescent nanoparticles in HeLa cells. Macromol Biosci. 2008;8(12):1135-1143.

86. Woodle MC, Lasic DD. Sterically stabilized liposomes. Biochim Biophys Acta. 1992;1113(2):171-199.

87. Elsabahy M, Wooley KL. Design of polymeric nanoparticles for biomedical delivery applications. Chem Soc Rev. 2012;41(7):2545-2561.

88. Cruz LJ, Tacken PJ, Fokkink R, Figdor CG. The influence of PEG chain length and targeting moiety on antibody-mediated delivery of nanoparticle vaccines to human dendritic cells. Biomaterials. 2011;32(28): 6791-6803.

89. Dos Santos T, Varela J, Lynch I, Salvati A, Dawson KA. Quantitative assessment of the comparative nanoparticle-uptake efficiency of a range of cell lines. Small. 2011;7(23):3341-3349.

90. Kim JA, Åberg C, Salvati A, Dawson KA. Role of cell cycle on the cellular uptake and dilution of nanoparticles in a cell population. Nat Nanotechnol. 2012;7(1):62-68.

91. Saftig P, Klumperman J. Lysosome biogenesis and lysosomal membrane proteins: trafficking meets function. Nat Rev Mol Cell Biol. 2009;10(9): 623-635.

92. Fischer HC, Hauck TS, Gómez-Aristizábal A, Chan WC. Exploring primary liver macrophages for studying quantum dot interactions with biological systems. Adv Mater. 2010;22(23):2520-2524.

93. Boussif O, Zanta MA, Behr JP. Optimized galenics improve in vitro gene transfer with cationic molecules up to 1000-fold. Gene Ther. 1996;3(12):1074-1080.

94. Moore NM, Sheppard CL, Barbour TR, Sakiyama-Elbert SE. The effect of endosomal escape peptides on in vitro gene delivery of polyethylene glycol-based vehicles. J Gene Med. 2008;10(10):1134-1149.

95. Caracciolo G, Caminiti R, Digman MA, Gratton E, Sanchez S. Efficient escape from endosomes determines the superior efficiency of multicomponent lipoplexes. J Phys Chem B. 2009;113(15):4995-4997.

96. Chu CJ, Dijkstra J, Lai MZ, Hong K, Szoka FC. Efficiency of cytoplasmic delivery by $\mathrm{pH}$-sensitive liposomes to cells in culture. Pharm Res. 1990;7(8):824-834.

97. Zuhorn IS, Bakowsky U, Polushkin E, et al. Nonbilayer phase of lipoplex-membrane mixture determines endosomal escape of genetic cargo and transfection efficiency. Mol Ther. 2005;11(5):801-810.
98. Kobayashi S, Nakase I, Kawabata N, et al. Cytosolic targeting of macromolecules using a $\mathrm{pH}$-dependent fusogenic peptide in combination with cationic liposomes. Bioconjug Chem. 2009;20(5):953-959.

99. $\mathrm{Mu} \mathrm{Q}$, Broughton DL, Yan B. Endosomal Leakage and Nuclear Translocation of Multiwalled Carbon Nanotubes: Developing a Model for Cell Uptake. Nano Lett. 2009;9(12):4370-4375.

100. AshaRani PV, Low Kah Mun G, Hande MP, Valiyaveettil S. Cytotoxicity and genotoxicity of silver nanoparticles in human cells. ACS Nano. 2009;3(2):279-290.

101. Huwyler J, Drewe J, Krähenbuhl S. Tumor targeting using liposomal antineoplastic drugs. Int J Nanomedicine. 2008;3(1):21-29.

102. Punnonen EL, Ryhänen K, Marjomäki VS. At reduced temperature, endocytic membrane traffic is blocked in multivesicular carrier endosomes in rat cardiac myocytes. Eur J Cell Biol. 1998;75(4): 344-352.

103. Ogris M, Wagner E, Steinlein P. A versatile assay to study cellular uptake of gene transfer complexes by flow cytometry. Biochim Biophys Acta. 2000;1474(2):237-243.

104. Leclerc L, Boudard D, Pourchez J, et al. Quantification of microsized fluorescent particles phagocytosis to a better knowledge of toxicity mechanisms. Inhal Toxicol. 2010;22(13):1091-1100.

105. Yang H, Lou C, Xu M, Wu C, Miyoshi H, Liu Y. Investigation of folate-conjugated fluorescent silica nanoparticles for targeting delivery to folate receptor-positive tumors and their internalization mechanism. Int J Nanomedicine. 2011;6:2023-2032.

106. Nuutila J, Lilius E-M. Flow cytometric quantitative determination of ingestion by phagocytes needs the distinguishing of overlapping populations of binding and ingesting cells. Cytometry A. 2005;65(2):93-102.

107. Drescher D, Giesen C, Traub H, Panne U, Kneipp J, Jakubowski N. Quantitative imaging of gold and silver nanoparticles in single eukaryotic cells by laser ablation ICP-MS. Anal Chem. 2012;84(22):9684-9688.

108. Bacallao R, Sohrab S, Phillips C. Guiding Principles of Specimen Preservation for Confocal Fluorescence Microscopy. In: Pawley JB, editor. Handbook of Biological Confocal Microscopy. 3rd ed. Madison, WI: Springer Science+Business Media; 2006:368-380.

109. Elsaesser A, Barnes CA, McKerr G, et al. Quantification of nanoparticle uptake by cells using an unbiased sampling method and electron microscopy. Nanomedicine (Lond). 2011;6(7):1189-1198.

110. Mühlfeld C, Mayhew TM, Gehr P, Rothen-Rutishauser B. A novel quantitative method for analyzing the distributions of nanoparticles between different tissue and intracellular compartments. J Aerosol Med. 2007;20(4):395-407.

111. Schmutz HR, Detampel P, Bühler T, Büttler A, Gygax B, Huwyler J. In vitro assessment of the formation of ceftriaxone-calcium precipitates in human plasma. J Pharm Sci. 2011;100(6):2300-2310.

112. Brandenberger $C$, Clift MJD, Vanhecke D, et al. Intracellular imaging of nanoparticles: is it an elemental mistake to believe what you see? Part Fibre Toxicol. 2010;7:15.

113. Mühlfeld C, Brandenberger C. Uptake of nanoparticles by cells: do you know their number? Nanomedicine (Lond). 2011;6(7):1149-1151; author reply 1153-1154.

114. Choi HS, Ashitate Y, Lee JH, et al. Rapid Translocation of Nanoparticles from the Lung Airspaces to the Body. Nat Biotechnol. 2010;28(12):1300-1303

115. Shim J, Seok Kang H, Park WS, Han SH, Kim J, Chang IS. Transdermal delivery of mixnoxidil with block copolymer nanoparticles. J Control Release. 2004;97(3):477-484.

116. Aggarwal N, Goindi S. Preparation and in vivo evaluation of solid lipid nanoparticles of griseofulvin for dermal use. J Biomed Nanotechnol. 2013;9(4):564-576.

117. Des Rieux A, Fievez V, Garinot M, SchneiderYJ, Préat V. Nanoparticles as potential oral delivery systems of proteins and vaccines: a mechanistic approach. J Control Release. 2006;116(1):1-27.

118. Xu Q, Zhang N, Qin W, Liu J, Jia Z, Liu H. Preparation, in vitro and in vivo evaluation of budesonide loaded core/shell nanofibers as oral colonic drug delivery system. J Nanosci Nanotechnol. 2013;13(1): $149-156$. 
119. Mager DE, Mody V, Xu C, et al. Physiologically based pharmacokinetic model for composite nanodevices: effect of charge and size on in vivo disposition. Pharm Res. 2012;29(9):2534-2542.

120. Petri-Fink A, Steitz B, Finka A, Salaklang J, Hofmann H. Effect of cell media on polymer coated superparamagnetic iron oxide nanoparticles (SPIONs): colloidal stability, cytotoxicity, and cellular uptake studies. Eur J Pharm Biopharm. 2008;68(1):129-137.

121. Kutscher HL, Chao P, Deshmukh M, et al. Threshold size for optimal passive pulmonary targeting and retention of rigid microparticles in rats. J Control Release. 2010;143(1):31-37.

122. Aneja MK, Geiger JP, Himmel A, Rudolph C. Targeted gene delivery to the lung. Expert Opin Drug Deliv. 2009;6(6):567-583.

123. Choi HS, Liu W, Misra P, et al. Renal clearance of quantum dots. Nat Biotechnol. 2007;25(10):1165-1170.

124. Maeda $H$. The enhanced permeability and retention (EPR) effect in tumor vasculature: the key role of tumor-selective macromolecular drug targeting. Adv Enzyme Regul. 2001;41:189-207.

125. Shah NB, Vercellotti GM, White JG, Fegan A, Wagner CR, Bischof JC. Blood-Nanoparticle Interactions and in Vivo Biodistribution: Impact of Surface PEG and Ligand Properties. Mol Pharm. Epub July 23, 2012.

126. Dobrovolskaia MA, Clogston JD, Neun BW, Hall JB, Patri AK, McNeil SE. Method for analysis of nanoparticle hemolytic properties in vitro. Nano Lett. 2008;8(8):2180-2187.

127. Yu T, Malugin A, Ghandehari H. Impact of silica nanoparticle design on cellular toxicity and hemolytic activity. ACS Nano. 2011;5(7): 5717-5728.

128. Quirion F, St-Pierre S. Reduction of the in vitro hemolytic activity of soybean lecithin liposomes by treatment with a block copolymer. Biophys Chem. 1991;40(2):129-134.

129. Paula AJ, Martinez DST, Araujo Júnior RT, Souza Filho AG, Alves OL. Suppression of the hemolytic effect of mesoporous silica nanoparticles after protein corona interaction: independence of the surface microchemical environment. J Braz Chem Soc. 2012;23(10):1807-1814.

130. Lynch I, Dawson KA. Protein-nanoparticle interactions. Nano Today. 2008;3(1-2):40-47.

131. Gasser M, Rothen-Rutishauser B, Krug HF, et al. The adsorption of biomolecules to multi-walled carbon nanotubes is influenced by both pulmonary surfactant lipids and surface chemistry. J Nanobiotechnology. 2010;8:31.

132. Gessner A, Waicz R, Lieske A, Paulke BR, Mäder K, Müller R. Nanoparticles with decreasing surface hydrophobicities: influence on plasma protein adsorption. Int J Pharm. 2000;196(2):245-249.

133. Duan X, Li Y. Physicochemical characteristics of nanoparticles affect circulation, biodistribution, cellular internalization, and trafficking. Small. 2013;9(9-10):1521-1532.

134. Arnida, Janát-Amsbury MM, Ray A, Peterson CM, Ghandehari H. Geometry and surface characteristics of gold nanoparticles influence their biodistribution and uptake by macrophages. Eur J Pharm Biopharm. 2011;77(3):417-423.

135. Bailon P, Palleroni A, Schaffer CA, et al. Rational design of a potent, long-lasting form of interferon: a $40 \mathrm{kDa}$ branched polyethylene glycol-conjugated interferon $\alpha-2 \mathrm{a}$ for the treatment of hepatitis $\mathrm{C}$. Bioconjug Chem. 2001;12(2):195-202.

136. Li SD, Huang L. Stealth nanoparticles: high density but sheddable PEG is a key for tumor targeting. J Control Release. 2010;145(3):178-181.

137. Lipka J, Semmler-Behnke M, Sperling RA, et al. Biodistribution of PEG-modified gold nanoparticles following intratracheal instillation and intravenous injection. Biomaterials. 2010;31(25):6574-6581.

138. Ishihara T, Takeda M, Sakamoto H, et al. Accelerated blood clearance phenomenon upon repeated injection of PEG-modified PLA-nanoparticles. Pharm Res. 2009;26(10):2270-2279.

139. Murthy AK, Stover RJ, Hardin WG, et al. Charged gold nanoparticles with essentially zero serum protein adsorption in undiluted fetal bovine serum. J Am Chem Soc. 2013;135(21):7799-7802.
140. Garnett MC, Kallinteri P. Nanomedicines and nanotoxicology: some physiological principles. Occup Med (Lond). 2006;56(5):307-311.

141. Svistounov D, Warren A, McNerney GP, et al. The Relationship between fenestrations, sieve plates and rafts in liver sinusoidal endothelial cells. PLoS ONE. 2012;7(9):e46134.

142. Gaumet M, Vargas A, Gurny R, Delie F. Nanoparticles for drug delivery: The need for precision in reporting particle size parameters. Eur J Pharm Biopharm. 2008;69(1):1-9.

143. Liu X, Huang N, Li H, Jin Q, Ji J. Surface and size effects on cell interaction of gold nanoparticles with both phagocytic and nonphagocytic cells. Langmuir. 2013;29(29);9138-9148.

144. Hirn S, Semmler-Behnke M, Schleh C, et al. Particle size-dependent and surface charge-dependent biodistribution of gold nanoparticles after intravenous administration. Eur J Pharm Biopharm. 2011;77(3): 407-416.

145. Zhang G, Yang Z, Lu W, et al. Influence of anchoring ligands and particle size on the colloidal stability and in vivo biodistribution of polyethylene glycol-coated gold nanoparticles in tumor-xenografted mice. Biomaterials. 2009;30(10):1928-1936.

146. Xie G, Sun J, Zhong G, Shi L, Zhang D. Biodistribution and toxicity of intravenously administered silica nanoparticles in mice. Arch Toxicol. 2010;84(3):183-190.

147. Huang X, Li L, Liu T, et al. The shape effect of mesoporous silica nanoparticles on biodistribution, clearance, and biocompatibility in vivo. ACS Nano. 2011;5(7):5390-5399.

148. Moghimi SM, Hunter AC, Andresen TL. Factors controlling nanoparticle pharmacokinetics: an integrated analysis and perspective. Annu Rev Pharmacol Toxicol. 2012;52:481-503.

149. Jain RK. Normalizing tumor microenvironment to treat cancer: bench to bedside to biomarkers. J Clin Oncol. 2013;31(17):2205-2218.

150. Wang J, Zhu X, Zhang X, et al. Disruption of zebrafish (Danio rerio) reproduction upon chronic exposure to $\mathrm{TiO}_{2}$ nanoparticles. Chemosphere. 2011;83(4):461-467.

151. Mahmoudi M, Hofmann H, Rothen-Rutishauser B, Petri-Fink A. Assessing the in vitro and in vivo toxicity of superparamagnetic iron oxide nanoparticles. Chem Rev. 2012;112(4):2323-2338.

152. Park JH, Gu L, von Maltzahn G, Ruoslahti E, Bhatia SN, Sailor MJ. Biodegradable luminescent porous silicon nanoparticles for in vivo applications. Nat Mater. 2009;8(4):331-336.

153. Chen K, Zhang J, Gu H. Dissolution from inside: a unique degradation behaviour of core-shell magnetic mesoporous silica nanoparticles and the effect of polyethyleneimine coating. J Mater Chem. 2012;22(41): 22005-22012.

154. Coyle P, Philcox JC, Carey LC, Rofe AM. Metallothionein: the multipurpose protein. Cell Mol Life Sci. 2002;59(4):627-647.

155. Levy M, Luciani N, Alloyeau D, et al. Long term in vivo biotransformation of iron oxide nanoparticles. Biomaterials. 2011;32(16): 3988-3999.

156. Akagi T, Higashi M, Kaneko T, Kida T, Akashi M. Hydrolytic and enzymatic degradation of nanoparticles based on amphiphilic poly(gamma-glutamic acid)-graft-L-phenylalanine copolymers. Biomacromolecules. 2006;7(1):297-303.

157. Park K, Kim JH, Nam YS, et al. Effect of polymer molecular weight on the tumor targeting characteristics of self-assembled glycol chitosan nanoparticles. J Control Release. 2007;122(3):305-314.

158. Ye L, Yong KT, Liu L, et al. A pilot study in non-human primates shows no adverse response to intravenous injection of quantum dots. Nat Nanotechnol. 2012;7(7):453-458.

159. Wilkinson K, Ekstrand-Hammarström B, Ahlinder L, et al. Visualization of custom-tailored iron oxide nanoparticles chemistry, uptake, and toxicity. Nanoscale. 2012;4(23):7383-7393.

160. Som C, Nowack B, Krug HF, Wick P. Toward the Development of Decision Supporting Tools That Can Be Used for Safe Production and Use of Nanomaterials. Acc Chem Res. Epub October 31, 2012. 
International Journal of Nanomedicine

Dovepress

\section{Publish your work in this journal}

The International Journal of Nanomedicine is an international, peerreviewed journal focusing on the application of nanotechnology in diagnostics, therapeutics, and drug delivery systems throughou the biomedical field. This journal is indexed on PubMed Central, MedLine, CAS, SciSearch ${ }^{\circledR}$, Current Contents ${ }^{\circledR} /$ Clinical Medicine,
Journal Citation Reports/Science Edition, EMBase, Scopus and the Elsevier Bibliographic databases. The manuscript management system is completely online and includes a very quick and fair peer-review system, which is all easy to use. Visit http://www.dovepress.com/ testimonials.php to read real quotes from published authors.

Submit your manuscript here: http://www.dovepress.com/international-journal-of-nanomedicine-journal 